\title{
El abogado Gemelli: memoria viajera y cultura letrada*/
} An Attorney Called Gemelli: Memoir of a Journey and its Times

\author{
Salvador Bernabéu Albert \\ Escuela de Estudios Hispano-Americanos, \\ Consejo Superior de Investigaciones Científicas, Sevilla
}

El trabajo aborda la biografía del viajero Gianfrancesco Gemelli Carreri (Radicena, 1651-Nápoles, 1725), quien realizó, entre otros viajes, una vuelta al mundo entre 1693 y 1698. Se contextualizan sus empresas europeas, se analiza la producción literaria y se resaltan las polémicas que rodearon su Giro del Mondo (1699-1700). La última parte del trabajo está dedicada a estudiar las circunstancias y riqueza de datos del relato de su periplo desde Manila a Acapulco: uno de los textos más completos e interesantes para conocer la travesía del Pacífico Septentrional.

Palabras clave: Galeón de Manila; Libros de viaje; Gianfrancesco Gemelli Carreri; Globalización;

Visiones del Pacífico; Vida cotidiana en los barcos.

This study offers a biographical sketch of the traveler Gianfrancesco Gemelli Carreri (Radicena, 1651-Naples, 1725), who undertook (among other travels) a trip around the world between 1693 and 1698. His European dealings are placed in context, his literary output scrutinized, and the controversies surrounding the publication of his Giro del Mondo (1699-1700) discussed. The latter part of the study examines the circumstances behind his journey from Manila to Acapulco and the richness of his account of it, one of the most detailed and fascinating texts we have of a passage across the northern Pacific.

KeYwords: The Manila Galleon; Travelers' Accounts; Gianfrancesco Gemelli Carreri; Globalization; Visions of the Pacific; Daily Life at Sea.

* Este trabajo se enmarca en el proyecto «El Pacífico Hispano: imágenes, conocimiento y poder» (PO9-HUM-5392), aprobado y financiado por la Junta de Andalucía (2010-2013). 


\section{Introducción}

El viaje alrededor del mundo del letrado napolitano Gianfrancesco Gemelli Carreri (1693-1698) sigue suscitando gran interés por varias razones. Realizado a finales del siglo XVII, sin embargo, sus numerosas ediciones, traducciones y lecturas durante el Setecientos lo convierten en uno de los primeros periplos de la Ilustración. ${ }^{1}$ Aunque los viajeros son tan antiguos como la humanidad, el siglo XVIII elevó a éstos y a la literatura que generaron a una posición privilegiada. Los numerosos libros de viajes que se editaron a lo largo de toda Europa convirtieron la temática en un subgénero con miles de seguidores en la centuria ilustrada. El interés por conocer el mundo empujó a numerosas personas a abandonar sus hogares y a enfrentarse a los peligros del camino y a los enigmas de los horizontes geográficos y mentales. Los viajeros del Setecientos no inventaron nada, lo nuevo fue el considerable aumento de su número, el enorme espacio que reconocieron, las mejoras en los instrumentos y su repercusión en el pensamiento y en la elaboración del pasado de la humanidad, aunque, como ya estudié en otro trabajo, hubo más persistencias que novedades. ${ }^{2}$

Gracias al éxito de esas múltiples empresas, los editores adquirieron -interviniendo directamente o por medio de intermediarios - un mayor protagonismo en la edición final de los textos, en la elección de los contenidos y en la disposición de las diversas partes, bien enriqueciéndolos con grabados, mapas, desplegables, etcétera, o bien adjuntándoles prólogos de personajes notables, apéndices diversos y documentos originales. En contraposición, para ser usados por el caminante, se multiplicaron las guías, las descripciones en pequeño formato y los itinerarios con un fin eminentemente práctico. Gracias a un público lector en alza y cada vez más exigente, los libros de viajes alcanzaron un gran éxito, siendo el Giro del Mondo (1699-1700) de Gemelli uno de los primeros best-seller de la centuria. Para entonces, nuestro personaje, que había empleado casi cinco años y medio en dar la vuelta al globo, tenía otros dos libros de viajes impresos, cuyas circunstancias abordaremos en el siguiente apartado. No era, por tanto, un escritor novel ni un viajero sin experiencia, si bien el éxito del Giro y la experiencia de un recorrido de esa envergadura le marcarían para el resto de su vida y lo entronarían en el parnaso de los más célebres viajeros de la

1 La primera edición está a caballo de ambas centurias, pues los seis tomos aparecieron entre septiembre de 1699 y febrero de 1700 .

2 Bernabéu, 2003, 36-55. 
Edad Moderna. Su obra, a caballo entre dos siglos, contribuyó a la historia cultural del Setecientos temprano, como señala el profesor Buccini: «come documento di un processo di transizione dalla Weltanschauung barocca a quella razionalistica ed erudita del primo Settecento». ${ }^{3}$

\section{De abogado a viajero: las razones de Gemelli}

Gianfrancesco Gemelli Carreri ${ }^{4}$ nació en 1651 en la región de Calabria, en el sur de Italia, concretamente en la villa de Radicena, pequeña población rodeada de campos de olivos, naranjos y otros árboles frutales. ${ }^{5}$ El núcleo principal se edificó junto a un convento de monjes basilios, que posteriormente ocuparon los dominicos. El fundador fue el padre Niccolò Severino de San Giorgio Morgeto, contando con la aprobación del gobernador español Domingo de Mendoza. El renovado edificio, ahora bajo la dirección de los hijos de Santo Domingo de Guzmán, se inauguró el 12 de marzo de 1537, renombrándose la iglesia dedicada a San Basilio como Santa María de la Misericordia. ${ }^{6} \mathrm{Me}$ he detenido en este edificio religioso porque el único familiar de Gemelli

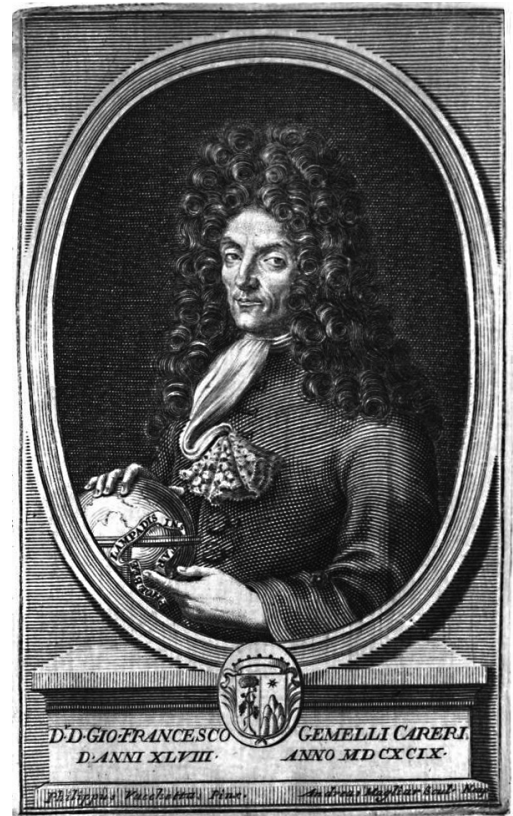

Giovani Francesco Gemelli Carreri. Grabado incluido en la traducción francesa de su libro: Voyage du tour $d u$ monde (1719).

3 Buccini, 1996, 256.

4 Sobre la biografía de nuestro viajero, véase Maccarrone, 2000.

5 El 12 de marzo de 1928 se fundó la ciudad de Taurianova para englobar a varias poblaciones como Radicena, Terranova Sappo Minulio, Jatrinoli y otros núcleos rurales. El nuevo topónimo se inspiró en Tauriana, ciudad costera que fue saqueada por los sarracenos en el año 950. Al parecer, sus habitantes huyeron hacia en interior de la península itálica, instalándose en los alrededores de Radicena.

6 El convento fue suprimido por las tropas francesas el 7 de agosto de 1809. La iglesia siguió siendo utilizada por los feligreses, pero se dedicó a la Virgen del Rosario en memoria de los padres dominicos. 
Carreri del que tenemos noticias es su hermano Giovani Battista, que llegó a ser abad del citado convento.

Aparte de este familiar directo, desconocemos los nombres y ocupaciones de sus padres y abuelos, o si tuvo otros hermanos y parientes. Tampoco poseemos datos sobre su infancia y juventud. Al parecer, estudió con los jesuitas y se graduó en leyes en la ciudad de Nápoles, capital del virreinato del mismo nombre bajo la soberanía del rey de España. La realización de los estudios jurídicos a lo largo de varios años y en una ciudad no especialmente barata, demuestran que Gianfrancisco contó con algún patrimonio heredado, una familia con ciertos recursos o con el apoyo de algún protector, lo que también podemos extender a su hermano, quien, como ya señalé, fue prior del convento dominico de Radicena.

De cualquier modo, fortuna y mecenas desaparecieron pronto, obligando a nuestro doctor a ejercer su oficio en diversas ciudades del reino de Nápoles desde los veinte años. Según escribió el propio Gemelli, su peregrinaje se extendió «por espacio de trece años en la judicatura y gobierno de muchas ciudades de aquel reino». ${ }^{7}$ El virreinato de Nápoles, incluido en el imperio hispano tras su cesión a Aragón por los franceses en 1504 (Tratado de Lyon), ocupaba buena parte de la mitad sur de la península itálica: un enorme y rico territorio que estuvo regido por diversos nobles españoles desde Carlos V hasta 1707, año en que pasó, durante la guerra de Sucesión española (1701-1713), al imperio austriaco. El origen napolitano de Gemelli explica el por qué entró con tanta facilidad en los dominios españoles de Asia y América durante su vuelta al mundo, aunque antes de iniciar este periplo, Gianfrancisco ya se había convertido en un experto viajero, experiencia que recogió en dos libros: Viaggi per Europa (Nápoles, Raillard, 1693) y La Campagna d'Ungheria (1704). Gracias a la publicación de ambos textos, la biografía de Gemelli se llena de datos y noticias a partir de 1685, contrastando esta abundancia de información con la escasez de datos hasta entonces. En los citados libros reproduce cartas, inserta reflexiones, cita a amigos y compañeros, confiesa sus filias y fobias, revela estados de ánimo, etcétera, lo que nos permite conocer mejor a nuestro huidizo personaje.

El primer viaje de Gemelli lo llevó por diversos estados y reinos de Europa. En 1685 inició su peregrinaje ascendiendo la península itálica hasta llegar a Turín, desde donde atravesó la frontera con Francia rumbo a

7 La cita pertenece a una carta de recomendación de la reina Eleonora de Polonia, que Gemelli incluye en su libro La Campagna d'Ungheria. Citada por Perujo, 2002, XII. 
París y al palacio de Versalles, monumental complejo que lo deslumbró. Tras visitar Inglaterra, de nuevo regresó al continente, desembarcando en los Países Bajos. El letrado calabrés visitó Brujas, Amberes, Ámsterdam, Nimega, Colonia y Viena, donde se incorporó a un grupo de mercaderes que llevaban vituallas y otros géneros con destino a Buda, ciudad en poder de los turcos que estaba sitiada por las tropas del emperador Leopoldo y otros aliados cristianos. En el campamento imperial, el jurista Gemelli se convirtió en soldado, cambió la toga por la coraza y participó en la batalla hasta la caída de la ciudad el 2 de septiembre de 1686.

Después de esta aventura guerrera, Gemelli regresó a Nápoles esperando encontrar un buen empleo. En su poder llevaba varias cartas de recomendación, como la escrita por la reina Eleonora de Polonia, duquesa de Lorena, que tenía su corte en la ciudad de Innsbruks y que solicitó para Gemelli una plaza en la real audiencia de Lecce o en la de Catanzaro. Sin embargo, el abogado calabrés no obtuvo nada de lo esperado y, defraudado, decidió regresar a los campos de batalla de Hungría, tomando parte en los combates de Siklos, Valpo y Mohacz.

Esta segunda participación voluntaria en la guerra santa contra los turcos le dio nuevas esperanzas para lograr un buen empleo en la administración virreinal, atreviéndose incluso a sugerir el puesto que deseaba: Juez de Vicaría perpetuo en la ciudad de Nápoles. Y para lograr su empeño se dirigió con constancia y convencimiento tanto a los grandes cargos del Imperio (como al duque de Alba, presidente del Consejo de Italia, o al conde de Oropeza, del Consejo de Estado de Su Majestad), como a los funcionarios locales, sin olvidar coleccionar nuevas cartas de recomendación de monarcas, consortes, duques, embajadores, nobles, compañeros de batallas, etcétera, que enviará regularmente al rey Carlos II de España y V de Nápoles. Además, desconfiando del poder de las recomendaciones escritas, Gemelli se trasladó a la corte madrileña donde, finalmente, consiguió un premio menor: la merced de dos bienios de auditor en tierras napolitanas, el primero en Lucca y el segundo en L'Aquila, además del título de Juez de Vicaría - que solicitaba insistentemente- pero sólo ad honorem. Las mercedes fueron recogidas en un real decreto, datado en Madrid el 10 de abril de 1689, destacando Carlos II «las buenas prendas de virtud, modestia, y letras que concurren en persona del dicho Doctor D. Juan Francisco Gemeli». ${ }^{8}$ Sin embargo, el abogado calabrés escribió desolado a su amigo

8 Ibidem, XVIII. 
Amato Danio desde la capital de la monarquía: «por el modo en que me he esforzado, y por los servicios con que creía haber adquirido algún mérito, concebía la ilusión de obtener algo más».9

Cumplidos los dos bienios en los tribunales napolitanos, y de nuevo sin trabajo, Gemelli, queriendo sumar nuevas hazañas y méritos a su currículum y alejarse de ciertos enemigos en la profesión, proyectó un nuevo viaje, ahora mucho más ambicioso que los dos anteriores: dar la vuelta al globo siguiendo el rumbo del oeste, esperando quizás a la vuelta conseguir nuevos protectores y ganarse la voluntad real con los que anular a sus enemigos y alcanzar puestos relevantes en la administración, como finalmente sucedió.

Pero antes de abordar su gran viaje, quiero insistir en las razones verdaderas que, al parecer, decidieron a Gemelli a realizar un viaje tan largo, esforzado y peligroso como el giro del mondo. En la dedicatoria de su libro Viaggi per Europa al virrey Francisco de Benavides, conde de Santisteban, fechada el 7 de febrero de 1693, el abogado calabrés le confesó la existencia de una infausta estrella que le había impedido seguir avanzando en la carrera judicial a pesar de su buen expediente y de las recomendaciones reunidas por todo el continente. Sin embargo, desconocemos quién o quiénes le obstaculizaron su ascenso a los principales puestos judiciales del virreinato napolitano. ¿Se trató de una estrategia del letrado para mover el ánimo del conde de Santisteban? Insisto, ¿un invento para ascender con rapidez a cargos que le dieran mayor estabilidad y prestigio en Nápoles?

La resolución a esta cuestión está lejos de resolverse, pero Gemelli porfió una y otra vez en la presencia de influyentes y poderosos perseguidores de su persona tanto en los tribunales de Nápoles como en el Consejo Supremo de Italia. Estos altos funcionarios tendrían la culpa de impedir que nuestro viajero pudiera seguir escalando peldaños en la administración virreinal. Por si quedaba alguna duda, en la segunda edición del Giro del Mondo (Napoli, 1708), el letrado calabrés señaló explícitamente: «Pero es también muy cierto, que ninguna otra causa me movió a emprender este otro, tan peligroso e incómodo [viaje], sino las injustas persecuciones, y los no debidos ultrajes que me ví forzado a sufrir». ${ }^{10}$ En conclusión, que la persecución en su ambiente letrado le llevó a tomar la decisión de dar la vuelta al mundo.

\footnotetext{
9 Ibidem, XIX.

10 Gemelli, 1708, vol. I, parte I, lib. I, cap. II, p. 13.
} 
Sin duda, esta persecución fue una de las principales causas de su periplo, pero no podemos olvidar otras menos dramáticas. Desde su primer libro, Gemelli apeló a la curiosidad como el principal motivo de visitar otras ciudades y recorrer nuevos paisajes, y así lo repitió en el Giro del Mondo. Incluso confesó a los lectores que dicha curiosidad era su parte más débil, llegando a censurar la falta de interés de sus paisanos por conocer otros países y otras culturas a pesar de la extraordinaria nómina de viajeros italianos en otras épocas, desde los clásicos a Marco Polo, Cristóbal Colón o Américo Vespucio.

\section{Cinco años, cinco meses, veinte días y un libro}

El sábado 13 de junio de 1693, Gemelli inició su aventura, embarcándose en una falúa napolitana que lo condujo hasta su natal Calabria, donde pasó sus últimas semanas en la península itálica antes de hacerse a la mar y alcanzar la primera escala de su largo periplo: la isla de Malta. A esta parada le siguieron numerosas travesías marítimas y peregrinaciones por desiertos, estepas, bosques, selvas y paisajes montañosos, donde visitó desde las más humildes aldeas a algunas de las mayores urbes de Asia y América, como Pekín o México. En su circunvalación de la tierra, el abogado calabrés empleó cinco años, cinco meses y veinte días, regresando a la ciudad del Vesubio el 3 de diciembre de 1698, festividad de san Francisco Javier, protector de los viajeros. Varios amigos, que habían salido a recibirle al camino cercano a Nápoles, lo acompañaron en su entronización a la ciudad que le vio partir.

Los primeros días, Gemelli se alojó en la casa de su compañero Castagnola y, posteriormente, vivió cinco meses en la residencia de su amigo Amato Danio, juez de la Gran Corte de la Vicaría. Durante ese tiempo - escribió el viajero- todo fue un ir y venir a tertulias y palacetes de la elite local, donde se le pidieron detalles de su larga aventura. El letrado calabrés se había convertido en una celebridad y los patricios napolitanos se lo disputaban para oír de sus labios los peligros y las maravillas de sus andanzas. Pero Gemelli, consciente del principal objetivo que le había llevado a pasar casi cinco años y medio lejos de su patria, no descuidó la publicación de su obra: el Giro del Mondo, cuya primera edición, en seis volúmenes, se imprimió en el taller napolitano de Giuseppe Roselli entre el 24 de septiembre de 1699 y el 24 de febrero de 1700. Un tiempo real- 
mente escaso dada la magnitud y la dificultad de la producción impresa. Además, Gemelli, que seguía sin trabajo, tuvo que multiplicar sus acciones y apariciones públicas, dedicando el primer volumen al nuevo virrey de Nápoles, Luis Francisco de la Cerda y Aragón, duque de Medinaceli (16951702), y el segundo a don Juan Francisco Pacheco y Girón, duque de Uceda, embajador de España ante la Santa Sede. A ambos les demandó su sombra protectora para detener las persecuciones de varios funcionarios que le habían llevado, como señalé anteriormente, a tomar el hábito de peregrino, cuyo magnífico fruto es la edición del Giro del Mondo: un extraordinario esfuerzo que espera, gracias a sus valores literarios y dedicatorias, se transforme en un encumbrado cargo administrativo

Sin embargo, los acontecimientos políticos parieron tiempos de desconcierto. A la muerte de Carlos II, El Hechizado, el conflicto internacional por la sucesión al trono de España sumió a media Europa en un sangriento conflicto entre 1701 y 1713. Finalmente, por la Paz de Utrecht, la Casa de Borbón se hizo con el imperio hispano, pero el virreinato de Nápoles, entre otros territorios, pasaron a ser gobernados por el emperador Carlos VI de Alemania, quien nombró en adelante a los virreyes napolitanos: primero el conde de Martinitz (1707) y posteriormente el príncipe de Teano (1707-1708), el cardenal Vincenzo Grimani (1707-1710) y un largo etcétera hasta 1734. Durante el conflicto, las intrigas se sucedieron en los cenáculos y tertulias napolitanas, si bien no hay constancia de que nuestro abogado viajero participase en alguna de ellas.

No obstante, Gemelli se mostró abiertamente pro-austriaco y aprovechó la llegada a Barcelona del archiduque Carlos, proclamado Carlos III por el bando austracista - y futuro emperador Carlos VI del Sacro Imperio Romano Germánico entre 1711 y 1740 —, para dirigirse a la ciudad condal y presentar sus libros a cuantos nobles y altos funcionarios encontró a su paso. Finalmente, el 11 de agosto de 1708 enseñó sus obras al archiduque austriaco y el 29 hizo lo mismo a su consorte Isabel Cristina en la villa de Orta. ${ }^{11}$ Los viajes, las recomendaciones y las audiencias dieron finalmente su fruto y, antes de acabar el año, Gemelli logró sus aspiraciones: ser nombrado Juez de Vicaría y Auditor de la Escuadra de las Galeras de Nápoles. ${ }^{12}$

11 Carlos VI de Alemania y la princesa Isabel Cristina de Brunswick contrajeron matrimonio el 1. ${ }^{\circ}$ de agosto de 1708 en la iglesia barcelonesa de Santa María del Mar.

12 Los principales episodios de este viaje a Barcelona son recogidos por Gemelli en su último libro: Aggiunta ai viaggi d'Europa, Napoli, Felice Mosca, 1711. 


\section{$\begin{array}{llll}G & I & R & O\end{array}$ \\ DEL MONDO \\ DEL DOTTOR}

D. GIO: FRANCESCO GEMEILI CARERI.

PARTE TRIM

Contenente le cafe più ragguarderoli vedute

NELLA TURCHIA.



$\begin{array}{llllllll}I & N & N & A & P & O & I & I_{x}\end{array}$

Nella Stamperia di Giu reppe R ofelli. r699.

Con licenza de' Superiori.

Portada original del primer volumen de la primera edición del Giro del Mondo (1699). 
Encumbrado en estos dos empleos de relevancia, Gemelli pasó los últimos años de su vida al servicio del emperador austriaco hasta su fallecimiento en Nápoles en 1725. Su fama de viajero no paró de crecer, como demuestran las reediciones de su obra y las traducciones a diversos idiomas. A su muerte, el niño nacido en la pequeña y humilde aldea de Radicena, rodeado de campos de olivos y naranjos, era un funcionario y escritor admirado en toda Europa, aunque la fama se fuera apagando conforme avanzase el Siglo llamado de las Luces por unos y de los Viajes, por otros. Señala Rousseau que sólo conviene viajar a una minoría, pues los periplos terminan por hacer al hombre bueno o malo: «no convienen sino a hombres bastante seguros de sí mismos para escuchar las lecciones del error sin dejarse seducir, y para ver el ejemplo del vicio sin dejarse arrastrar». No sabemos lo que le ocurrió a Gemelli, pues los detalles de su vida se volvieron a difuminar tras alcanzar los anhelados cargos bajo la administración austriaca, desconociéndose sus actividades durante el primer cuarto del siglo XVIII.

Este vacío dio pié a numerosas leyendas y conjeturas sobre su vida y su obra, que fueron creciendo al mismo ritmo que sus libros se fueron reeditando y traduciendo incluso en vida del autor. El Giro (1699-1700) tuvo cinco ediciones hasta 1727, tres de ellas impresas en Venecia. Además, apareció editado en las obras completas del abogado calabrés y llegaron a publicarse algunos resúmenes. En cuanto a las traducciones, la vuelta al mundo de Gemelli se editó en ingles en el tomo cuarto de A Collection of Voyages and Travels, some now first printed from original manuscripts, others Translated... and now first published in English (London, Awnsham and John Churchill, 1704). Y al francés en 1719: Voyage du tour du monde, traduit de l'italien de Gemelli Careri, par M. L. N., 6 vols. (Paris, chez Etienne Ganeau, 1719). A pesar del interés para los lectores en castellano — pues dos volúmenes están dedicados a las posesiones hispanas de Asia y América-, nunca apareció completo en español.

Pero volviendo al desconocimiento de la vida de Gemelli en el Nápoles austriaco, hay que remarcar que la ausencia de noticias generó, con el tiempo, numerosas conjeturas: se comentó que su peregrinación estuvo causada por conflictos familiares, que se vio envuelto en dos casos judiciales o que nunca había salió de Nápoles, escribiendo su Giro del Mondo mientras convalecía de una enfermedad causada por una epidemia. El abogado calabrés, aún en vida, conoció tanto los halagos como las acusaciones, principalmente de ser un farsante y un plagiario. Tras su muerte, 
y hasta el siglo $\mathrm{XX}$, aparecieron los escritos hagiográficos al mismo ritmo que los que le acusaban de impostor, farsante y embaucador. Por ejemplo, en el año 1900 se editó en Bérgamo uno de los libros más críticos con nuestro viajero: Il viaggiatore Gemelli Careri e il suo «Giro del Mondo», de Alberto Magnaghi. ${ }^{13}$ Este escritor lo acusó de haber copiado a otros viajeros anteriores y, para demostrar la falsedad de su obra, comparó letra a letra la relación de la visita de Gemelli al emperador Kam-Hi de China, recogida en el volumen IV de su Giro, con la descrita por el padre jesuita francés Louis Le Compte (1655-1728) en Lettres sur l'État présent de la Chine (Paris, 1697). La copia es casi literal, apareciendo la obra del francés tres años antes del libro gemelliano, lo que le bastó a Magnaghi, junto a otros ejemplos, para desacreditarlo.

Nos encontramos, sin duda, ante un problema no sólo de la obra de Gemelli, sino de la literatura de viajes en general, pues como señala Michèle Guéret-Laferté: «Es preciso destacar además que, si toda la literatura manuscrita está sujeta a sufrir deformaciones, incomprensiones, añadidos, supresiones, distorsiones, como una parte inherente de su proceso de difusión, la literatura de viajes ofrece un terreno ideal para la proliferación de este tipo de prácticas textuales». ${ }^{14}$ Sin duda, el texto de Gemelli está lleno de préstamos de otras obras, ya que el calabrés no es un descubridor, aunque descubra varias regiones del globo para muchos lectores. Muchos viajeros lo precedieron y, además, el propio autor reconoce explícitamente haber leído varias crónicas y relatos sobre las regiones que iba a recorrer en su obra. Pero Gemelli realizó, sin duda, el viaje, y buena parte de sus escritos son originales..$^{15}$ Por ello, el Giro del Mondo también tuvo y tiene sus defensores, abogados de la veracidad de su peregrinaje mundial, justificando la incorporación a su narración de textos ajenos a su pluma tanto por el deseo de completar lo vivido, como por la necesidad de incorporar datos o sucesos que otros informantes le proporcionaban para que su mirada abarcara más allá del horizonte, aunque normalmente estas noticias las pasa por el tamiz crítico, como cuando escribe, en mitad del océano Pacífico, sobre las míticas islas Rica de Oro y Rica de Plata.

Sin embargo, queda pendiente la explicación acerca de la incorporación de algunos fragmentos de otros autores que Gemelli hace suyos, como

\footnotetext{
13 Magnaghi, 1900.

14 Guéret-Laferté, 1994, 11.

15 Esta postura es la que defendió Magnaghi, 1900.
} 
la supuesta visita al emperador de China, episodio que al parecer nunca ocurrió y que el calabrés copia del jesuita Le Compte. Aquí debemos de preguntarnos sobre las elecciones y las manipulaciones de los textos en relación con las nuevas exigencias comerciales y técnicas editoriales en los inicios del siglo XVIII. Desde el siglo XVI, nace en Europa primero y en el resto del globo después una gran demanda de informaciones, descripciones y narraciones sobre los espacios desconocidos del planeta, que se acentuará conforme avance la centuria ilustrada. Para satisfacer esa demanda, se van a crear unos modelos que los editores intentan mejorar e ilustrar para llegar a un público cada vez más exigente.

Sabemos que Gemelli, a pesar de la dureza de los caminos y las incomodidades de los barcos, redactó un diario donde recogió sus vivencias y otras noticias que iba adquiriendo en el camino. Este diario, después de casi cinco años y medio, tuvo que ser muy voluminoso - quizás repartido en varios cuadernos-, a los que debía sumarle otras anotaciones sueltas, dibujos, esquemas, etcétera. Ese material pronto se convirtió en una obra en seis volúmenes, aparecidos entre 1699 y 1700, lo que hace pensar que contó con una o varias personas para la creación del manuscrito que finalmente se envió a la imprenta de Giuseppe Roselli.

No sólo el escaso tiempo que Gemelli tuvo avala esta hipótesis, sino que además sabemos que el calabrés estuvo entretenido en acudir a varias tertulias y residencias para contar sus hazañas. El principal colaborador en la construcción literaria del Giro fue el humanista Matteo Egizio, destacado intelectual de la época que ayudó a Gemelli y a otros escritores a pulir y ordenar sus obras antes de imprimirlas. ${ }^{16} \mathrm{~A}$ ambos, o a uno de ellos, debemos atribuirle el ampliar, completar y enriquecer el diario con varios textos de otros autores, algunos con nombre y apellidos y otros anónimos. Ese sería el principal cargo contra Gemelli: el trufar su testimonio personal con descripciones y noticias de otros libros, una práctica que era habitual en la época y que, desde luego, no invalida la veracidad del viaje, la riqueza de gran parte de sus capítulos y la utilidad de sus observaciones. Además, la mayoría de los estudiosos del Giro están de acuerdo en que una de las partes más gemellianas es la travesía del galeón, de la que trataré a continuación.

16 Sobre este interesante personaje, véase Ussia, 1977. 


\section{«La più terribile e lunga navigazione»}

Efectivamente, los defensores de la autenticidad del viaje de Gemelli han remarcado la veracidad de los datos y episodios reunidos en los dos últimos libros del Giro del Mondo: el V, dedicado a Filipinas y a la jornada en el galeón de Manila, y el VI, que recoge su paso por México y su regreso a Europa.

Gemelli aprovechó la necesaria etapa marítima para trasladarse de Asia a América —el viaje en el galeón de Manila, también conocido como la nao de China - para narrar con gran lujo de detalles la navegación desde el puerto de Cavite, en las inmediaciones de Manila, hasta la bahía de Acapulco, en la Nueva España: uno de los trayectos marítimos más importantes y desconocidos del planeta, por lo que la publicación de informaciones detalladas de la jornada oceánica fue muy atractiva y útil para los geógrafos, los comerciantes y los amantes de los viajes del Setecientos, aunque también para los mandos militares y navales de las potencias enemigas de España, que encontraron en la obra de Gemelli interesantes noticias sobre la ruta y las dificultades en la navegación de los barcos españoles por el Pacífico Septentrional.

Hasta la aparición del Giro, el único relato editado de la singladura del galeón de Manila se encontraba en la obra del padre Pedro Cubero Sebastián, Breve relación de la peregrinación que ha hecho de la mayor parte del mundo, editado en Madrid en 1680 y dos años después en Nápoles. Sin embargo, la narración de Cubero, enviado como misionero a las Indias Orientales por la Sagrada Congregación de Propaganda Fide (Roma), es más parca en noticias sobre el viaje; lo que le interesaba al sacerdote zaragozano eran los asuntos religiosos y la evangelización de China y Japón. ${ }^{17}$

La experiencia marítima marcó a nuestro abogado calabrés por la dureza, los peligros y las incomodidades del viaje, al que calificó, en varias ocasiones, como «La più terribile, e lunga navigazione, che sia al Mondo», añadiendo con rotundidad: «Sperimentai io buona parte di questa miseria». ${ }^{18}$ Gemelli se embarcó en la nao San José, que levó anclas el viernes 29 de junio de 1696 del puerto de Cavite y llegó a Acapulco el 19 de ene-

17 Cubero, 2007. El espacio que el misionero dedica al viaje en el galeón se reduce a un breve capítulo, concretamente el XLV: «Cuenta el Autor la dilatada, y penosa navegación desde las Islas Filipinas al puerto de Acapulco, con lo más notable de ella» (338-344).

18 Libro terzo, 255 y 308. 
ro de 1697. En total, el viaje se prolongó durante 204 jornadas. ${ }^{19}$ En el galeón se embarcaron doscientas personas entre pasajeros, marinos, pilotos y diversos nombramientos reales, siendo el de general el más solicitado. Pero el puesto más importante era el de piloto mayor, que recayó en el portugués, nacido en la isla de Madeira, Pedro Fernández, siendo asistido por dos ayudantes, uno de los cuales era el sevillano Isidoro Montes de Oca.

Aunque la llegada al puerto mexicano fue un poco tardía, el San José realizó un viaje transoceánico que podemos calificar de «normal». Los pasajeros y la oficialidad tuvieron problemas para salir del laberinto del archipiélago filipino, navegaron sin novedad reseñable hasta las islas Marianas y, a partir de ellas, soportaron los fríos, las tormentas, los mares picados e incluso el granizo frecuente en el Pacífico Norte. Los diferentes cálculos de los pilotos respecto a la longitud en la que se encontraba el galeón nos ilustra sobre la dificultad de alcanzar la costa americana a pesar de la ayuda de las «señas», diversas plantas flotantes que se alejaban cientos de millas del litoral del Nuevo Mundo, anunciando su proximidad. En el viaje de 1696-1697, si bien los pilotos esperaban avistar tierra hacia el 20 de noviembre, hubo que esperar al 14 de diciembre para descubrir la isla de Santa Catalina (California). Gemelli también participó de alguna forma de este error, pues había apostado con un tripulante que se vería tierra el 21 de noviembre, perdiendo dos botones de oro con esmeraldas.

A pesar de las constantes manifestaciones de Gemelli de la dureza del viaje, la travesía del San José no fue de las más infortunadas, como demuestra la baja cifra de muertos durante la travesía, tan sólo cinco personas, todas ellas en el mes de diciembre: un marinero el día primero, un enfermo el 7, un ayudante del piloto el 17, otro marinero el 18 y el capitán de Mar y Guerra el 19. Evidentemente, esto no anula las numerosas incomodidades a bordo (mareos, falta de espacio, escasez de agua y alimentos, malos olores, picaduras de chinches y piojos, etcétera) y la sensación de peligro que soportaron los pasajeros durante varios meses. Gemelli pudo paliar algunas de esas incomodidades al lograr alojarse en el camarote del guardián del galeón ( «buona cameretta per porvi il mio letto, e robe» ${ }^{20}$ ), con quien mantuvo una relación tirante durante las últimas semanas de navegación por negarle ciertos alimentos que compartían al principio.

19 Informe sobre este viaje en el Archivo General de Indias, Filipinas, 122 y Filipinas, 17, r1, n 15.

20 Gemelli, 1708, 256. 
Antes de seguir adelante, quisiera señalar que Gemelli pudo afrontar económicamente el viaje — cuyo pasaje valía veinte pesos de a ocho- gracias a sus actividades como comerciante, ocupación que venía realizando desde que salió de Nápoles, pero que ahora intensifica debido a las oportunidades que encuentra con el embarco de mercadería oriental en el galeón. Gemelli oculta esta actividad al ser ilegal para un extranjero, pero, al llegar a Acapulco, cuenta en su relato que bajó de la nao acompañando a la imagen de la Virgen María que llevaban en el galeón hasta la iglesia parroquial: «Ritornai la sera a dormire nel galeone, per non rimaner cosi la roba sotto la custodia dello schiavo, che, per trascuratezza, avrebbe potuto farla danneggiare». ${ }^{21}$ A esto se uniría el testimonio de una de las dos cartas incorporadas al final de su libro sobre China: «En Cantón, el 29 de abril de 1698. Señor: Ya me he permitido el honor de escribiros por medio de los bajeles ingleses, y de avisaros que había comprado las 50 tazas para chocolate, con sus platos, que vos deseabais y que os mandaré por el R. P. Tuccio vuestro compatriota [...] Vuestro muy humilde, y muy devoto servidor, Jean Basset.» ${ }^{22}$

Gemelli no pasó desapercibido en el galeón, como lo demuestra que el general le pidiese asistirle judicialmente para resolver algunas peleas y diferencias surgidas en el barco, o que en el Tribunal de Señas, mascarada donde se juzgaba a los principales cargos y pasajeros del galeón, fuese acusado de comer demasiadas cachorritas, teniendo que donar a los marineros y grumetes cierta cantidad de dinero o regalos para salvarse de una «sentencia de muerte». Otro dato que corrobora el interés que despertó el viajero italiano fueron las numerosas relaciones establecidas con los principales cargos del galeón y con los religiosos — principalmente los jesuitasembarcados. Y al pisar tierra: «Habiéndose informado sobre mi persona, los oficiales reales me hicieron muchísimas cortesías y me ofrecieron sus servicios», siendo invitado a desayunar por el gobernador de Acapulco, don Francisco Meca. ${ }^{23}$

\section{Los espacios y la escritura}

A pesar de las incomodidades, privaciones y peligros, Gemelli no dejó de escribir su diario. Por una anécdota que recoge el Giro, conocemos la

21 Gemelli, 1708, 353.

22 Citado por Perujo, 2002, LV.

23 Gemelli, 1700, 353. 
pasión y la constancia del abogado calabrés por la observación y la redacción: «Veggendomi il Contestabile del Vascello scrivere tutto ciò, nel mio libricciuolo, cominciò a farsene beffe», a lo que respondió el italiano tirándole el sombrero en la cara, aunque se quedó con las ganas — según confiesa- de romperle un palo en la cabeza. ${ }^{24}$ Dicho diario fue la base principal sobre la que se construyó el libro tercero del volumen quinto, dedicado a la navegación entre Manila y Acapulco. Dicho libro está dividido en seis capítulos, el último de los cuales destaca por su mayor extensión:

\section{LIBRO TERZO}

1. Pericolosissima navigaziobe dalle Filippine in America. Prima \&ossa fino al Varadero (pp. 255-261).

2. Si continua il viaggio fino al Porto di Ticao (pp. 262-268).

3. Navigazione fino alle Isole Mariane (pp. 269-277).

4. Scoprimento, e conquista delle Isole Mariane (pp. 277-282).

5. Fattezze, Religione, Frutta, Clima, e maravigliose Barche dell'Isole Mariane (283-287).

6. Lunghissima, e spaventevole navigazione fino al porto d'Acapulco (pp. 287-354).

Una rápida mirada a este listado de contenidos nos permite distinguir tres partes diferentes: la navegación desde Manila hasta las islas Marianas, que ocupa los tres primeros apartados; una narración de la conquista de las citadas islas, seguida de una historia natural y humana, a las que dedica los capítulos cuarto y quinto, y, finalmente, una larga crónica de la navegación entre las Marianas y Acapulco: un enorme sector del gran océano, lleno de privaciones y peligros, que ponía a prueba, en cada singladura, a hombres y barcos.

Como he señalado, los tres primeros capítulos cuentan la navegación jornada a jornada, ofreciéndonos variados e interesantes datos sobre la geografía, los habitantes y la naturaleza de las Filipinas. Se trata de una navegación conocida, aunque no faltan los sobresaltos por la peligrosidad de la ruta, plagada de escollos, farallones e islotes, corrientes contrarias y vientos traicioneros, hasta desembocar en el mar abierto por el estrecho de San

24 Gemelli, 1700, 293. 
Bernardino, entre las islas de Camarines y Samal. Poco a poco van apareciendo las digresiones en la narración, como la que compara las dificultades del viaje de ida a México con la facilidad de la vuelta (de Acapulco a Manila), lo que le hará confesar que uno de los principales fallos de su circunvalación del globo fue iniciarlo rumbo a poniente.

Los capítulos cuarto y quinto están dedicados al descubrimiento, conquista, evangelización, población y naturaleza de las islas Marianas, las que avistaron a partir del 6 de septiembre de 1696, terminando su narración con una detallada descripción de las pequeñas embarcaciones empleadas por los isleños. Su estructura y versatilidad lo dejaron tan admirado, que mandó dibujar un grabado que incluyó en su Giro.

El sexto y último capítulo se ocupa de la larga navegación entre las Marianas y el puerto de Acapulco. Como ya señalé, su mayor extensión contrasta con los anteriores capítulos, lo que permite insertar, entre las anotaciones diarias de vientos, observaciones astronómicas y rumbos realizados, varios excursos sobre la declinación de la brújula, las imaginarias islas Rica de Oro y Rica de Plata, la expedición de don Álvaro de Mendaña a las islas Salomón (1595-1596), la ínsula de Doña María Laxara, las miserias del galeón - las que compara con algunas de las Siete Plagas de Egipto-, las enormes ganancias que se conseguían en el viaje, la Audiencia de Señas, las enfermedades que aparecen durante la larga travesía (el berbén y el Mal de Holanda), la expedición de Sebastián Vizcaíno al Noroeste, la descripción del litoral mexicano y la llegada a Acapulco.

Efectivamente, Gemelli recoge casi obsesivamente las observaciones astronómicas de los pilotos, los acontecimientos de la navegación, las miserias de la vida a bordo, los imprevistos de un océano poco pacífico, las injusticias, etcétera. Pero a pesar de las noticias navales y astronómicas, el diario del calabrés difiere de los realizados por los capitanes y pilotos del galeón, donde señalan día a día las latitudes, longitudes, rumbo, distancia realizada, el estado del tiempo, etcétera. A Gemelli le interesan esos datos, pero resumidos en los principales hitos que explican la ruta realiza por los españoles en el Pacífico Septentrional entre Manila y Acapulco.

Al abordar el viaje del galeón, Gemelli narra una experiencia que implica un desplazamiento marítimo del que es protagonista y, como tal, testigo. El relato se articula siguiendo el recorrido de la nave desde el puerto de salida al de llegada. Este viaje lo utiliza el autor para la construcción de un clímax narrativo a partir del encadenamiento de los sucesos diarios y de la expectativa que genera en los lectores de que el barco 
llegue sano y salvo a su destino mexicano, por lo que no se priva de citar los naufragios y las derrotas fracasadas por los malos tiempos o por los errores de los pilotos.

El texto que finalmente se editó en el Libro Cuarto de su Giro del Mondo se basa, como ya señalé, en un diario donde el calabrés recoge las incidencias del trayecto, las islas que divisan (o que imaginan), las observaciones astronómicas, la vida a bordo, la alegría por ver tierra y los últimos trabajos hasta desembarcar en Acapulco. Es decir, que los acontecimientos se ordenan a partir de la cronología que da cuenta del viaje. En la narración del mismo se impone una mayor frescura, un aumento de los episodios cotidianos, de anécdotas y de referencias a la religiosidad que impone la fragilidad del hombre y la nave ante la inmensidad del océano. Este tono más directo se debe tanto a la experiencia que sufre el propio viajero en un entorno nuevo, hostil e impredecible, como a la falta de referencias, pues el viaje del galeón era bastante desconocido.

Pero además de las experiencias del día a día en un cascarón de madera entre el mar y el cielo, el texto incluye otras noticias y relatos recogidos de diversos informantes embarcados en el San José. El abogado nos revela algunos de ellos: los jesuitas Juan Yrigoyen, Antonio Borgia y Pedro Antonio Martínez, quienes lo documentan, entre otras cosas, sobre la misión que regentaba la Compañía de Jesús en dicho archipiélago, así como el contramaestre, que le refiere los pormenores de su recalada en las Marianas en anteriores navegaciones. Otros informantes son el capitán Manuel Argüelles, que le da noticias sobre las enormes ganancias que se obtenían en el comercio del galeón; uno de los ayudantes del piloto, que le facilita un mapa y una relación del viaje de Vizcaíno y, finalmente, un enigmático fraile de San Juan de Dios que le informó sobre un ataque a los indios del Cabo San Lucas en el transcurso de otra expedición. Estas informaciones, que seguramente serían algunas de las muchas recogidas en los tediosos días en la mar, nutrieron digresiones de diversa naturaleza que enriquecieron el texto.

En resumen, gracias a estos informantes y a otros anónimos, Gemelli introduce en la crónica diaria del viaje numerosos excursos geográficos, históricos, náuticos, fantásticos, etcétera, que son el factor distintivo de los relatos de viaje. Informaciones, noticias y descripciones que van a enriquecer la narración y que proporcionan al lector de ayer y de hoy numerosos datos sobre el pasado del océano Pacífico. Además, Gemelli utilizó al menos dos crónicas escritas: la obra del jesuita Francisco Colin, Labor 
evangélica, ministerios apostólicos de los obreros de la Compañía de Jesús, fundación, y progresos de su provincia en las islas Filipinas (Madrid, José Fernández de Buendía, 1663), de donde extrae la información sobre el viaje de Álvaro de Mendaña e Isabel de Barreto a las islas Salomón (1595-1596), y un mapa y una relación del viaje de Sebastián Vizcaíno, redactado probablemente por el carmelita fray Antonio de la Ascensión, que utiliza para incluir un resumen de la citada expedición a la Alta California entre 1602 y $1603 .{ }^{25}$ Este texto y mapa le fueron facilitados por el ayudante de piloto Isidoro Montes de Oca.

Llegados a este punto, creo que es bueno recordar la intervención decisiva de Matteo Egizio en la redacción final del Giro del Mondo. Sin embargo, es difícil saber hasta qué punto pudo intervenir en esta parte de la obra, pues pienso que la pluma de Gemelli está más presente que nunca tanto por la frescura de la escritura y la ausencia de elementos fantásticos, como por los datos de personas reales que aporta y la equidad de sus juicios y comentarios. Aunque, como en todo relato de viaje que se precie, no falten episodios maravillosos, como la visión del singular ocaso del sol acaecido el 10 de septiembre: «Si vide il Cielo di color violaceo con nubbi Verdi.» Un prodigio para Gemelli, que fue ratificado por sus compañeros jesuitas. ${ }^{26}$ La belleza de la Naturaleza en estado puro, que el abogado calabrés supo admirar en mitad de inmenso océano Pacífico.

\section{Bibliografía}

Bernabéu Albert, Salvador: «¿Ilusos o ilustrados? Novedades y pervivencias en los viajes del Setecientos», Revista de Occidente, 260, 2003, 36-55.

Buccini, S.: «Coerenza metodologica nel Giro del Mondo di Giovanni Francesco Gemelli Careri», Annali d'Italianistica, 14, 1996, 246-256.

Cubero Sebastián, Pedro: Peregrinación del mundo, Madrid, Miraguano Ediciones-Ediciones Polifemo, 2007 [1680].

Gemelli Carreri, Giovanni Francesco: Giro del Mondo del dottor ..., 6 vols., Napoli, nella Stamperia di Giuseppe Roselli, 1769-1700.

Gemelli Carreri, Giovanni Francesco: Giro del Mondo del Dott. D. ... Parte quinta contenente le cose più ragguardevoli vedute nell'isole Filippine, In Napoli, nella stamperia di Giuseppe Roselli, 1700.

25 Sobre los viajes de Vizcaíno, Portillo, 1982, 181-238.

26 Gemelli, 1700, 288. 
Gemelli Carreri, Giovanni Francesco: Giro del Mondo, 2. ${ }^{a}$ edición, Napoli, Roselli, 1708, vol. I, parte I, lib. I, cap. II, p. 13.

Gemelli Carreri, Giovanni Francesco: Viaje a la Nueva España, México, UNAM, 2002 [1976].

Guéret-Laferté, Michéle: Sur les Routes de L'Empire Mongol. Ordre et rhétorique des relations de voyage aux XIIIe et XIVe siècles, Paris, Honoré Champion, 1994.

Maccarrone Amuso, A.: Gianfrancesco Gemelli Careri. L'Ulisse del XVII secolo, Roma, Gangemi, 2000.

Magnaghi, A.: Il viaggiatore Gemelli Careri (secolo XVII) e il suo "Giro del Mondo», Bergamo, Cattaneo, 1900.

Perujo, Francisca: «Estudio preliminar, traducción y notas», en Gemelli Carreri, Giovanni Francesco: Viaje a la Nueva España, México, UNAM, 2002 [1976], VII-XCVIII.

Portillo, Álvaro del: Descubrimientos y exploraciones en las costas de California, 1532-1650, Madrid, Rialp, 1982.

Ussia, Salvatore: L'epistolario di Matteo Egizio e la cultura napolitana del primo Settecento, Roma, Liguori Editore, 1977. 